\title{
Left atrial sarcoma: a case report
}

\author{
Ljupka Dimitrovska'*, \\ Jure Dolenc', \\ Matija Jelenc', \\ Zvezdana Dolenc- \\ Stražar², \\ Tomislav Klokočovnik'
}

'University Medical Centre Ljubljana, Ljubljana, Slovenia

${ }^{2}$ Faculty of Medicine, University of Ljubljana Ljubljana, Slovenia
KEYWORDS: cardiac tumor, malignant intimal sarcoma, cardiac imaging. CITATION: Cardiol Croat. 2017;12(4):151. | https://doi.org/10.15836/ccar2017.151

*ADDRESS FOR CORRESPONDENCE: Ljupka Dimitrovska, Univerzitetni klinični center Ljubljana, Zaloška cesta 7, 1000 Ljubljana, Slovenia. / Phone: +386-51-754-857 / E-mail: ljupkadim@gmail.com

ORCID: Ljupka Dimitrovska, http://orcid.org/0000-0002-2467-5438 • Jure Dolenc, http://orcid.org/0000-0002-9444-4352

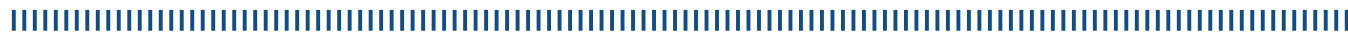
Introduction: The purpose of this paper is to present the case of patient with a primary cardiac tumor in the left atrium', which was suspected to be sarcoma.

Case report: 51-year-old female was transferred from peripheral hospital for further diagnosis due to a suspected tumor in left atrium. She sought medical attention after experiencing shortness of breath fatigue, fainting under light exertion. Echocardiography was performed, which showed a left atrial mass measuring $4 \times 3 \times 2 \mathrm{~cm}$, growing from the inferolateral wall (Figure 1). The mass was occupying more than half the left atrium and was pushing or adherent to the posterior leaflet of mitral valve therefore causing mild to moderate functional mitral stenosis. Depending solely on the location of the tumor it was suspected that this is probably myxoma. MRI confirmed the echo findings (Figure 2A), probabbly a sessile myxoma. However, MRI could not confirm nor execlude sarcoma. PET CT showed a hypermetabolic left atrial mass without any distant metastasis (Figure 2B). Biopsy of tumor mass was not performed because of the high risk for embolic complications. In view of the extent of the mass and the limited exposure, we proceeded to perform an auto transplantation - heart explanation with ex vivo resection and reconstruction of the left atrium with CorMatrix patch. The patient returned to the operating room on the second postoperative day due to cardiac tamponade and required the insertion of a permanent pacemaker for complete heart block prior to her discharge 3 weeks following surgery. The histology revealed a spindle cell tumor consistent with a malignant intimal sarcoma. No further adjuvant therapy was given. Ten months following surgery, she remains symptom free with no evidence of any cardiac masses on echocardiography or distant metastases on CT scan.

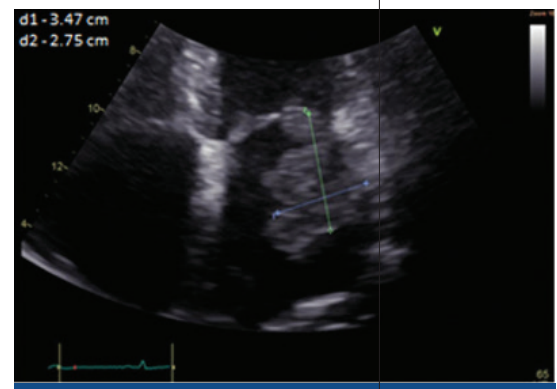

FIGURE 1. Echocardiography demonstrating a left atrial mass that was occupying left atrium and was pushing or adherent to the posterior leaflet of mitral valve.

RECEIVED:

March 11, 2017

ACCEPTED:

April 6, 2017

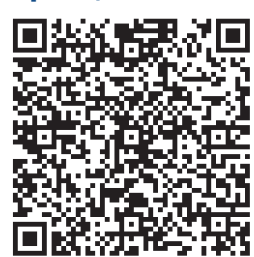

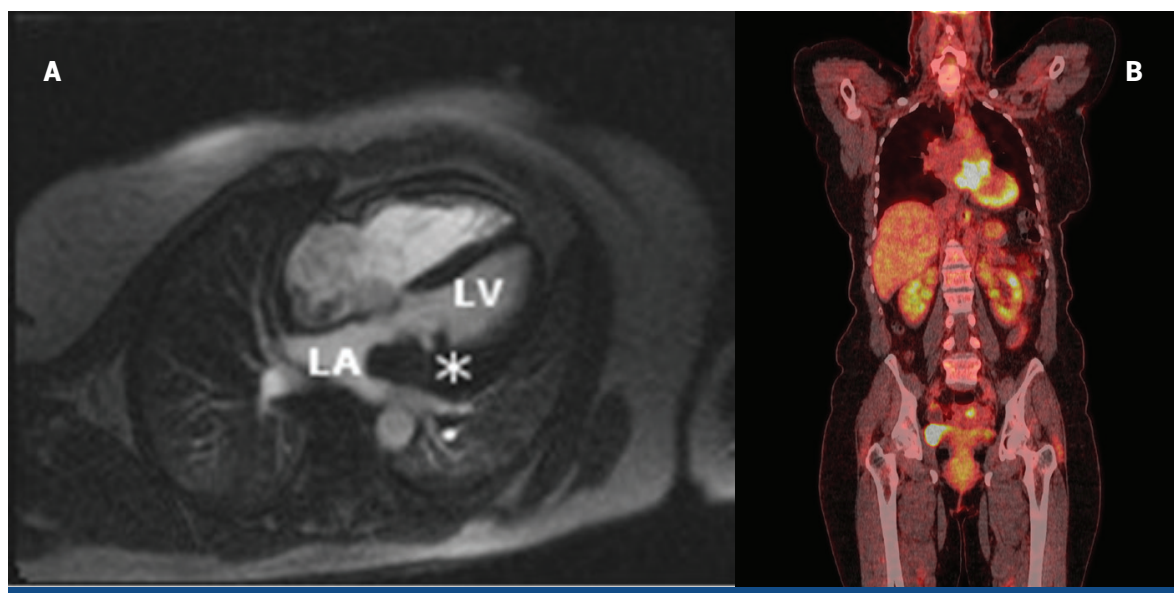

FIGURE 2. Cardiac magnetic resonance (A) and PET-CT (B), demonstrating the mass in the left atrium. PET CT did not show any signs of metastasis in the rest of the body. 